program has undertaken the organizing conferences and professional workshops and publishing handbooks and studies of important education markets. Study in Poland has promoted Polish higher education in China, India, Vietnam, Thailand,

The formula determining government funding of a university has been changed to include an incentive to internationalize.

Philippines, Malaysia, Indonesia, Russia, Ukraine, Kazakhstan, and the United States, as well as in Spain, Belgium, the Netherlands, and France. During the period since the program started, the number of foreign students in Polish higher education institutions increased by 30 percent.

The ruling political party, Platforma Obywatelska (liberal), in its 2007 election program declared support for internationalization of higher education in Poland and for the Study in Poland program. As yet no steps have been taken in this direction, but lobbying efforts are in progress.

\section{The Future}

The Conference of Rectors of Academic Schools in Poland has affirmed that, to become truly international, Polish higher education institutions will need to activate the field of transnational education, enact policies to attract international students and academic staff, and develop international curricula. Without greater understanding of the international higher education landscape, the process of marginalization of Polish schools will continue. Because of the centralized nature of the public system, funding will be needed to ensure internationalization.

\section{Double- and Joint-Degree Programs: Double Benefits or Double Counting?}

\section{JANE KNIGHT}

Jane Knight is adjunct professor at the Ontario Institute for Studies in Education, University of Toronto, Canada. E-mail: janeknight@sympatico.ca.

$\mathbf{T}^{\mathrm{n}}$ the current landscape of higher education, international 1 joint-, double-, and combined-degree programs perform an important role and will likely rise in numbers and influence in the coming years. This internationalization strategy brings important benefits to individuals, institutions, and national and regional education systems. Regarding these programs, interest is expanding, but confusion is also rising about what they characterize and entail.

For many academics and policymakers, double- and jointdegree programs are welcomed as a natural extension of exchange and mobility. For others, they are perceived as a troublesome development leading to double counting of academic work and the thin edge of academic fraud. A broad range of reactions exist because of the diversity of these program models, the involvement of different types of institutions, the uncertainty related to quality assurance and qualifications, and the ethics used in designing the academic workload or new competencies required for the granting of a joint, double, multiple, or combined degree.

\section{Proposed Working Definitions}

A plethora of words are used to describe these programs-double, multiple, trinational, joint, integrated, collaborative, combined, concurrent, consecutive, overlapping, conjoint, parallel, simultaneous, and common. These terms convey different

For many academics and policymakers, doubleand joint-degree programs are welcomed as a natural extension of exchange and mobility.

meanings among people within and across countries, complicating the situation. The following definitions may provide clarity and common understanding: A joint-degree program awards one joint qualification upon completion of the collaborative program requirements established by the partner institutions. A double-degree program awards two individual qualifications at equivalent levels upon completion of the collaborative program requirements established by the two partner institutions. A combined-degree program awards two different qualifications at consecutive levels upon completion of the requirements established by the partner institutions.

\section{BENEFITS}

Collaborative-degree programs can lead to a deeper and more sustainable relationship than many internationalization strategies and create such academic benefits as innovation of curriculum, exchange of professors and researchers, and increased access to expertise and research networks. Students are attracted to double degrees for enhanced career opportunities, an international study and life experience, and the perception that "two degrees for one" means decreased workload and tuition fees. At the national and regional level, they are seen to contribute to increased status, competitiveness, and capacity building.

\section{Challenges}

The benefits of joint-, double-, and combined-degree programs 
are numerous and diverse but so are the problems. Different regulatory systems, academic calendars, credit systems, tuition and scholarship schemes, teaching languages and approaches, and examination requirements create only some of the technical requirements to be met by the participating institutions.

National and university regulations and customs differ among countries and present challenges for the design and implementation of international collaborative programs-regulations preventing students from enrolling in more than one university at a time, laws requiring students to spend their last year or semester at the home university, or practices mandating the recruitment and selection of students. Nonrecognition and limitations on the number of courses or credits taken at a partner university raise additional barriers. Dissimilar academic years can create problems for student mobility but may provide more opportunities for faculty exchange. Evaluation requirements and procedures often present obstacles to double-degree programs.

Much of the concern rests with the double counting of the same course credits and workload for two or more qualifications

Quality assurance and accreditation constitute fundamental factors, but national accreditation systems do not exist in all countries or may differ enormously. Some bodies focus on the program and others on the institutional level; many concentrate on inputs, and others look at process or outputs. Currently, the best-case scenario involves the completion of accreditation by each partner institution in the double-, joint-, or combined-degree program. Certain professional programs are evaluated by international accreditation agencies like ABET or EQUIS, but currently institutions are more likely to have their home programs accredited than the double- or jointdegree programs. A relevant issue concerns whether national, regional, or international accreditation is the best route for international collaborative programs.

Recognition of the qualifications from the various collaborative programs forms the most vexing issue. Only a few countries, although the numbers are rising, allow a domestic university legally to confer a joint qualification in partnership with a foreign institution. The student would get a formal diploma from one university and an unofficial certificate from the other, or others, indicating that it was a joint collaborative program. For some students, the international nature, rather than the qualification, of the academic program composed the most significant aspect. For many though, this is not the case as credentialism is increasingly relevant for students and their careers.

Employers, academic institutions, and credential evaluation agencies must be aware of the granting and recognition of double or multiple qualifications. Some double, multiple and combined degrees are perceived as more "legitimate" than others, but this impression is difficult to prove. Much of the concern rests with the double counting of the same course credits and workload for two or more qualifications. This has led to the "two for the cost of one" label for double degrees. Cost in this case is not only measured in monetary terms but also student workload.

The diversity of models used to determine the completion requirements for double- and multiple-degree programs is problematic. No clarity exists on whether requirements are based on (I) the number of completed courses and credits, (2) the student workload, or (3) required outcome and competency. These three approaches lead to different explanations and arguments to support the legitimacy of the double and multiple degrees awarded. Many would argue that attributing the same course workload toward two or more degrees from two or more institutions in different countries devalues the validity of a qualification. Others believe that if students meet the stated learning outcomes and competencies required for a qualification the credential is legitimate. This logic infers that double and multiple degrees, based on a set of core courses or competencies, are academically legitimate; and it is the process for recognizing these qualifications that requires more attention not the completion requirements per se. Both arguments have validity, but the variety of program models prevents a clear resolution to the question of perceived and actual legitimacy.

The higher education sector must work out a common understanding of joint, double, and combined programs and iron out the academic issues concerning working in different national regulatory frameworks, cultures, and practices. A rigorous debate on the vexing questions of accreditation, recognition, and legitimacy of the qualifications needs to take place to ensure that international collaborative programs and their awards are respected and recognized by students, higher education institutions, and employers around the world.

\section{International Students in the United States: Open Doors}

\section{Survey}

\section{Patricia Chow and Rachel Marcus}

Patricia Chow is senior program officer and Rachel Marcus is research officer at the Institute of International Education. E-mail: iieresearch@iie.org. Open Doors Web site: http://opendoors.iietnetwork.org.

$\mathrm{D}$ uring the 2007/08 academic year, the number of international students in the United States reached a record high of 623,805 , a 7 percent increase over the prior year and the first significant increase since 200I/02. Students enrolling for the 